\title{
Anterior urethral diverticulum: A rare presentation
}

\author{
Annavarupu Gopalkrishna, Somendra Mohan Sharma, B. Ananda \\ J. Watumull Global Hospital and Research Centre, Mount Abu, Rajasthan, India
}

Address for correspondence: Dr. Somendra Mohan Sharma, J. Watumull Global Hospital and Research Centre, Delwara Road, Mount Abu - 307 501, Rajasthan, India. E-mail: drsomendra@gmail.com

\section{ABSTRACT}

Congenital anomalies of the urogenital tract are the most common anomalies found in the foetus, neonates and infants, but anterior urethral valves and diverticula are rare. Here, we present a case with congenital anterior urethral diverticulum associated with patent ductus arteriosus and polydactyly.

\section{KEY WORDS}

Anterior urethral cyst; anterior urethral diverticulum; anterior urethral valve; congenital; patent ductus arteriosus; polydactyly

\section{INTRODUCTION}

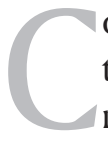

ongenital anomalies of the urogenital tract are the most common anomalies found in the foetus, neonates and infants, ${ }^{[1]}$ but anterior urethral valves and diverticula are rare. ${ }^{[2]}$ Here, we present a case with congenital anterior urethral diverticulum. What is peculiar with this case is that the same patient had two more congenital anomalies (patent ductus arteriosus and polydactyly). However, we could not find any inter-relation in published literature.

\section{CASE REPORT}

A 9-year-old male child presented with dribbling after micturition and swelling at the distal shaft of the penis since birth [Figure 1]. He also had a history of patent ductus arteriosus, which was discovered in his early childhood,

\begin{tabular}{|l|l|}
\hline \multicolumn{2}{|c|}{ Access this article online } \\
\hline Quick Response Code: & Website: \\
\hline & www.ijps.org \\
\cline { 2 - 3 } & Dol: \\
\hline
\end{tabular}

for which percutaneous closure was done about a year ago. The patient also had bilateral polydactyly feet (six toes in each foot) [Figure 2].

On clinical and ultrasonographic examination, we found that the patient had congenital anterior urethral diverticulum [Figure 3].

The diverticulum was excised through a degloving skin incision [Figure 4]. Postoperatively, the child had normal stream and no follow-up dribbling [Figure 5].

\section{DISCUSSION}

Anterior urethral diverticulum is an outpouching of the anterior urethra through the corpus spongiosum.

\footnotetext{
This is an open access article distributed under the terms of the Creative Commons Attribution-NonCommercial-ShareAlike 3.0 License, which allows others to remix, tweak, and build upon the work non-commercially, as long as the author is credited and the new creations are licensed under the identical terms.

For reprints contact: reprints@medknow.com

How to cite this article: Gopalkrishna A, Sharma SM, Ananda B. Anterior urethral diverticulum: A rare presentation. Indian J Plast Surg 2016;49:265-7.
} 


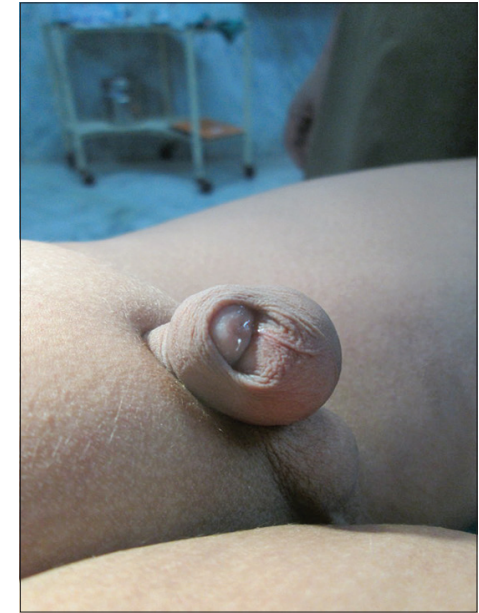

Figure 1: Pre-operative view of anterior urethral diverticulum

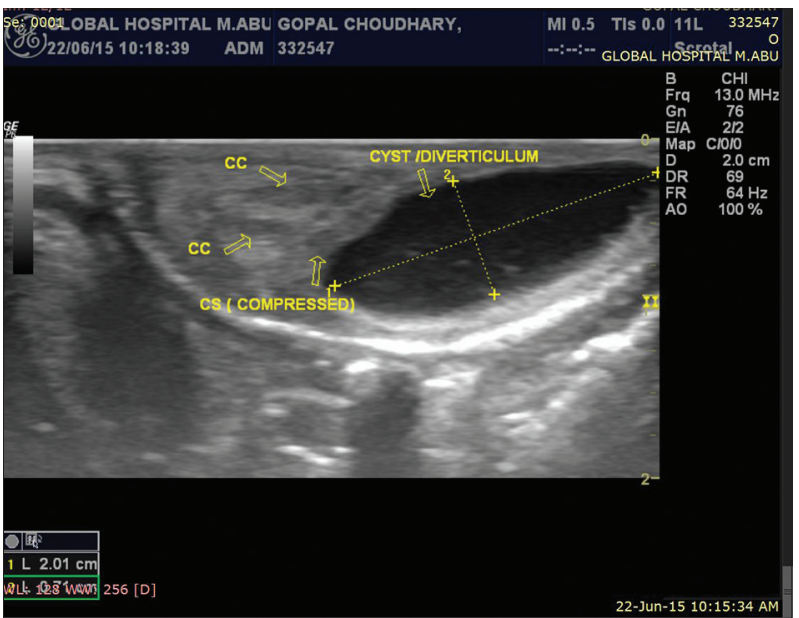

Figure 3: Ultrasonography image of anterior urethral diverticulum

Some authors consider anterior urethral valves and diverticula as the same entity, and some consider them to be two distinct entities. ${ }^{[2]}$ It has been suggested that valves cause proximal urethral dilatation with the formation of a sac-like diverticulum. On the other hand, some believe that the distal lip of a diverticulum rises and acts like a valve when the diverticulum is distended with urine. ${ }^{[2]}$ An important differentiating point may be that while congenital anterior urethral valve is covered by corpus spongiosum, congenital anterior urethral diverticulum protrudes through it, and hence, it is covered only by skin. ${ }^{[3]}$

We believe that this distinction is only theoretical, and practically, both are the same because congenital anterior urethral valve, at the time of presentation, is indistinguishable from congenital anterior urethral diverticulum, and the symptoms and management are the same.

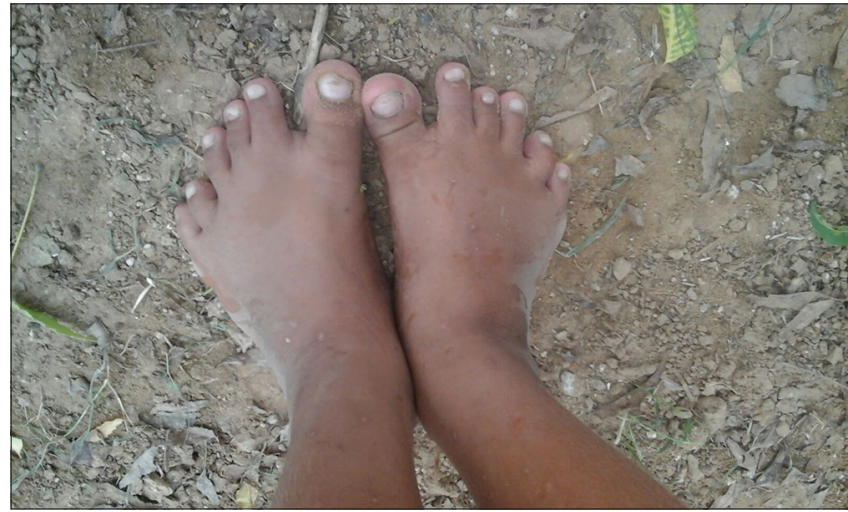

Figure 2: Polydactyly of both feet

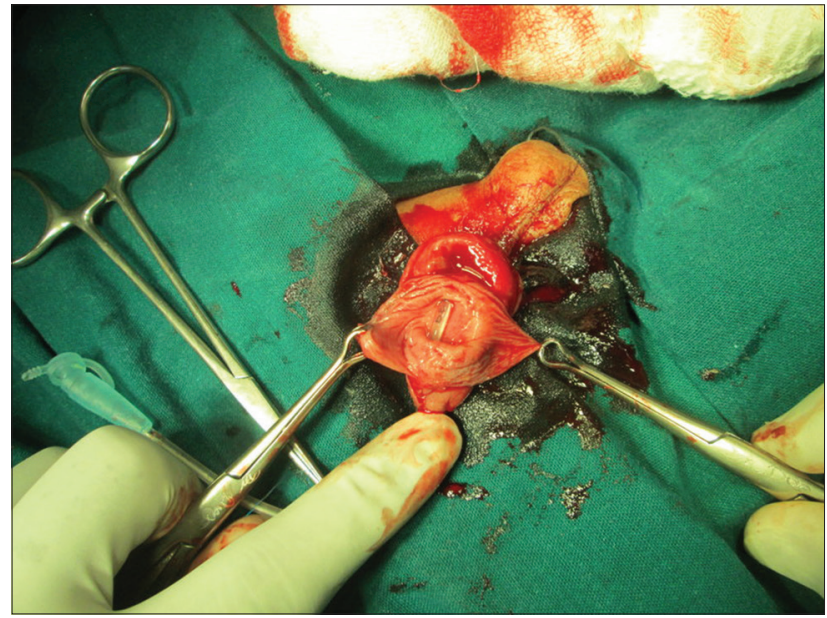

Figure 4: Intra-operative view showing the opened diverticulum with catheter in situ

There are generally two types of anterior urethral diverticula. ${ }^{[2]}$ Those arising from the ventral surface of bulbar urethra are most common and present with obstructive symptoms; while the others, arising from the ventral surface of the urethra near the penile tip are rare, and are more prone to calculus formation. ${ }^{[2]}$

There are various embryologic theories of anterior urethral diverticulum formation such as: (a) developmental defect resulting in the weakness of corpus spongiosum; ${ }^{[2]}$ (b) an incomplete hypospadias; ${ }^{[4]}$ (c) cystic dilatation of urethral glands; (d) sequestration of an epithelial rest and (e) congenital anterior urethral valve and congenital anterior urethral diverticulum arising from the anterior lip of ruptured syringocele of Cowper's duct. ${ }^{[2]}$

Patients usually present complaining of poor urinary flow, post-micturition dribbling, penile ballooning and/or urinary tract infection. ${ }^{[4]}$ 


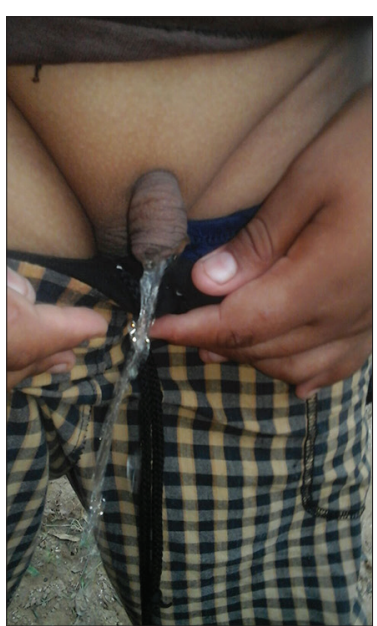

Figure 5: Post-operative view showing a good urinary stream with no fistula

The diagnosis of congenital anterior urethral diverticulum/ valve can easily be done by a clinical examination, ultrasonography, retrograde urethrography, voiding cystourethrography and/or urethroscopy.

The surgical management may be endoscopic or open. In endoscopic surgery, the pouch still persists, hence it can develop a flap again, and re-operation may be required. In these cases, regular endoscopic surveillance is needed.

Open approach, on the other hand, obviates this, but fistula formation is a potential complication, and in some cases, temporary urinary diversion may be required.

\section{CONCLUSION}

Congenital anomalies of the urogenital tract are the most common anomalies found in the foetus, neonates and infants, but anterior urethral valves and diverticula are rare. They can be easily diagnosed and managed by surgical repair.

\section{Financial support and sponsorship}

Nil.

\section{Conflicts of interest}

There are no conflicts of interest.

\section{REFERENCES}

1. Jana M, Gupta AK, Prasad KR, Goel S, Tambade VD, Sinha U. Pictorial essay: Congenital anomalies of male urethra in children. Indian J Radiol Imaging 2011;21:38-45.

2. Levin TL, Han B, Little BP. Congenital anomalies of the male urethra. Pediatr Radiol 2007;37:851-62.

3. Paulhac P, Fourcade L, Lesaux N, Alain JL, Colombeau P. Anterior urethral valves and diverticula. BJU Int 2003;92:506-9.

4. Quoraishi SH, Khan F, Besarani D, Patil K. Congenital anterior urethral diverticulum in a male teenager: A case report and review of the literature. Case Rep Urol 2011;2011:738638. 